\title{
Reliability of Time-to-boundary Measures Estimated from Center of Pressure during Single- leg Standing by Healthy Young Adults
}

\author{
Yuki Yamanaka $^{1)}$, Ryo Okuma ${ }^{2)}$, Junpei Sasadai ${ }^{3)}$, Eri Fuji ${ }^{3)}$, Satoshi Takai ${ }^{4)}$, \\ Hiroshi Shinohara ${ }^{5)}$, Yukio Urabe ${ }^{3)}$ \\ 1) Faculty of Health Care Sciences, Himeji Dokkyo University: 7-2-1 Kamiouno, Hyogo, 670-0896, \\ Japan.TEL: +81 79-223-0908,E-mail: yukiyama@gm.himeji-du.ac.jp \\ 2) Department of Rehabilitation, Toranomon Branch Hospital \\ 3) Graduate School of Biomedical \& Health Sciences, Hiroshima University \\ 4) Eldervilla Himi Elderly Healthcare Facility \\ 5) Southern Orthopedics and Internal Medicine Clinic
}

\begin{abstract}
Purpose] Time-to-boundary (TTB) measures estimate the time it would take for center of pressure (COP) to reach the boundary of the base of support if COP were to continue on its trajectory at its instantaneous velocity. This study aimed to determine the reliability of TTB measures obtained from healthy young adults during single-leg standing. [Subjects and Methods] Thirteen young adults (11 male, 2 female) performed three, 30 -second trials of single-leg standing on a force plate. Ground reaction forces were recorded at a sampling frequency of $50 \mathrm{~Hz}$ and the data from 10 to 20 seconds were analyzed. TTB measures were absolute minimum, mean of minimum and SD of minimum in the ML and AP directions. Traditional COP measures were mean velocity, SD of COP, range of COP in the ML and AP directions and root mean square area. [Results] The intraclass correlation coefficient $\left(\mathrm{ICC}_{2.1}\right)$ of TTB measures were ranged from 0.50 to 0.69 and those of the COP measures ranged from 0.17 to 0.64 . [Conclusion] The reliabilities of TTB measures were slightly better than those of the traditional COP measures. Acceptable reliability of all TTB measures can be achieved when 3 trials are averaged during the same testing day. Key words: Center of pressure, Postural stability, Single-leg standing
\end{abstract}

(This article was submitted May 17, 2012, and was accepted Jun. 11, 2012)

\section{INTRODUCTION}

Postural stability is often characterized by body sway estimated from center of pressure (COP) measures during upright standing posture ${ }^{1-3}$. In previous studies, it has been reported that COP sway of single-leg standing increases markedly with decreased postural stability resulting from ankle joint disorders, such as ankle sprain ${ }^{4}$. However, there are limitations to the statistical method for the traditional COP measures because the COP sway has been shown to be a non-stationary time series ${ }^{5)}$. Thus, it is necessary that we would find a reliable method of assessing spatiotemporal characteristics of postural stability.

Time-to-boundary (TTB) measures provide a novel approach to quantifying postural stability measures ${ }^{6-9)}$. TTB measures estimate the time it would take for COP to reach the boundary of the base of support if COP were to continue on its trajectory at its instantaneous velocity. We think TTB measures are a reliable method of assessing spatiotemporal characteristics of postural stability since they allow assessment of a time series of the first derivative of COP and the location on the foot where the excursions are occurring. However, few studies have reported on the reliability of TTB measures during single-leg standing ${ }^{7)}$, and it has not be suffi- ciently examined. The purpose of this study is to determine the reliability of TTB measures obtained from healthy young adults during single-leg standing.

\section{SUBJECTS AND METHODS}

\section{Subjects}

Thirteen young adults (11 male and 2 female, mean age: $24.2 \pm 3.1$ years; mean height: $171.8 \pm 8.3 \mathrm{~cm}$; mean weight: $69.9 \pm 12.3 \mathrm{~kg}$ ) participated in this study. Subjects who had any impairment of the lower extremity or vestibular pathologies that could adversely affect their balance were excluded from the study. The study procedures were approved by the Hiroshima University Division of Physical Therapy and Occupational Therapy Sciences Ethics Board (\#1011), and the subjects provided their informed consent prior to participation.

\section{Methods}

The participants performed three, 30-second trials of single-leg standing with a delay of 60 seconds between tests. They stood barefoot on their dominant (right) leg on a force plate (AccGait, AMTI Inc), and lifted their non-dominant 
(left) leg forward by flexing it at the hip and knee. They were also instructed to cross their arms over the chest and keep focusing on a visual target placed at eye height approximately $2 \mathrm{~m}$ in front of them. Ground reaction forces were recorded at a sampling frequency of $50 \mathrm{~Hz}$. The time series of COP data was filtered with a forth-order zero lag, low-pass filter using a cutoff frequency of $5 \mathrm{~Hz}$, and data from 10 to 20 seconds of each trial were used in further data analysis.

TTB measures were calculated as previously described ${ }^{6-8)}$. The foot was modeled as a rectangle based on the location of the foot on the force plate, to allow for separation of the anterior-posterior (AP) and medio-lateral (ML) components of COP. For each COP ML data point, the COP ML position and velocity were used to calculate TTB ML. At any time point, if the COP MLi was moving medially, the distance between COP MLi and the medial border of the foot was calculated (Fig. 1). This distance was divided by the corresponding instaneous velocity of COP MLi to calculate the time it would take the COP MLi to reach the medial border of the foot, if it were to continue moving in the same direction without a change in velocity. A time series of 500 TTB ML and TTB AP measures was generated. A typical TTB series shows a sequence of peaks and valleys with each valley representing a change in direction of COP (Fig. 2). To identify the minimum valleys, we computed COP derivatives: the first derivative values were used to identify signal minimums and maximums, and the second derivative values were used to compute the minimum.

TTB measures were: the absolute minimum (TTB abs min), mean of minimum (TTB mean valley) and standard deviation of minimum samples (TTB SD) in the ML and AP directions respectively. Traditional COP measures were: mean velocity of COP excursions ( $\mathrm{mv} \mathrm{COP}$ ), standard deviation of COP excursions (SD COP), range of COP excursions (range $\mathrm{COP}$ ) in the $\mathrm{ML}$ and AP directions respectively and root mean square area (RMS area).

The reliability of each parameter was estimated using the intraclass correlation coefficient $\left(\mathrm{ICC}_{2.1}\right)$ because it considers random effects over time for the retest study and the effects of the evaluators. In addition, it has generally been used to estimate the reliability of COP measures in previous studies. The $95 \%$ confidence interval of $\mathrm{ICC}_{2.1}$ was calculated to provide an indication of the precision of the coefficients. ICC values greater than 0.75 are considered as excellent reliability, from 0.40 to 0.75 as fair to good reliability, and less than 0.40 as poor reliability ${ }^{10)}$. The Spearman-Brown prophecy formula was used to estimate the number of trials $(k)$ required to achieve the expected reliability ${ }^{11)}$. The formula is $\mathrm{R}_{\mathrm{k}}=k \mathrm{R} / 1+(k-1) \mathrm{R}$. Where $R_{k}$ is the theorized reliability and $R$ is the reliability of the present measure. Microsoft Office Excel 2003 (Microsoft Inc.) and Scilab 5.2.2 (INRIA) were used to perform the statistical analysis. A p value of $<0.05$ was considered to be statistically significant.

\section{RESULTS}

$\mathrm{ICC}_{2.1}$ of TTB measures ranged from 0.50 to 0.69 and those of the COP measures ranged from 0.17 to 0.64

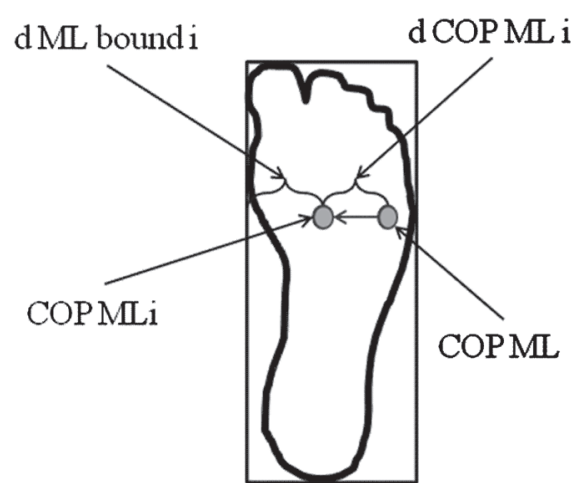

Fig. 1. Time to boundary (TTB) calculations in the ML direction: This figure shows how TTB was calculated using center of pressure (COP) excursions in the medio-lateral direction. The formula is TTB ML i $=\mathrm{d}$ ML bound $\mathrm{i} /$ ( $\mathrm{d}$ COP $\mathrm{ML} \mathrm{i} / 0.02 \mathrm{sec})$.

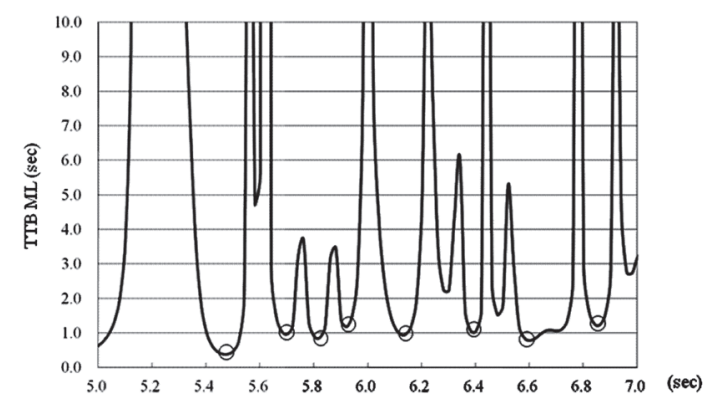

Fig. 2. A typical time to boundary (TTB) series in the ML direction: This figure shows the TTB ML data stream from 2 seconds of single-leg standing (represented by circles).

(Table 1). TTB measures showed excellent reliability (ICC $>0.75$ ) in averages of at least 3 trials during the same testing day, while the COP measures required more than 5 trials, except for mv COP and RMS area. The lengths of the foot in the AP and ML directions were $25.0 \pm 1.4 \mathrm{~cm}$ and $10.0 \pm$ $0.7 \mathrm{~cm}$ respectively.

\section{DISCUSSION}

The results of the present study indicate that the reliabilities of TTB measures were slightly better than those of the traditional COP measures. In addition, acceptable reliability of all TTB measures was achieved in 3 trials, averaged on the same testing day. In a previous study, Hertel et al. ${ }^{7)}$ reported that intra-session reliabilities of TTB measures were comparable to traditional COP measures for young healthy females. However, it has also been reported that the reliability of traditional COP measures cannot always be assumed during quiet stance ${ }^{12}$. The present study revealed that TTB measures are more reliable than the traditional COP measures. 
Table 1. The reliability of TTB and traditional COP measures

\begin{tabular}{llllll}
\hline & & Mean $\pm \mathrm{SD}$ & $\mathrm{ICC}_{2.1}$ & $95 \% \mathrm{CI}_{\text {of }} \mathrm{ICC}_{2.1}$ & $\mathrm{k}$ \\
\hline TTB measures & & & & & \\
TTB ML abs min & $(\mathrm{sec})$ & $0.44 \pm 0.10$ & 0.53 & $0.19-0.80$ & 3 \\
TTB ML mean valley & $(\mathrm{sec})$ & $0.89 \pm 0.18$ & 0.69 & $0.40-0.88$ & 2 \\
TTB ML SD & $(\mathrm{sec})$ & $0.24 \pm 0.07$ & 0.59 & $0.23-0.84$ & 2 \\
TTB AP abs min & $(\mathrm{sec})$ & $1.61 \pm 0.39$ & 0.50 & $0.16-0.79$ & 3 \\
TTB AP mean valley & $(\mathrm{sec})$ & $3.04 \pm 0.77$ & 0.61 & $0.25-0.85$ & 2 \\
TTB AP SD & $(\mathrm{sec})$ & $0.73 \pm 0.26$ & 0.50 & $0.16-0.79$ & 3 \\
COP measures & & & & & \\
mv COP ML & $(\mathrm{cm} / \mathrm{sec})$ & $2.61 \pm 0.53$ & 0.64 & $0.34-0.86$ & 2 \\
SD COP ML & $(\mathrm{cm})$ & $0.50 \pm 0.06$ & 0.17 & $-0.14-0.57$ & 13 \\
range COP ML & $(\mathrm{cm})$ & $2.26 \pm 0.28$ & 0.17 & $-0.15-0.57$ & 14 \\
mv COP AP & $(\mathrm{cm} / \mathrm{sec})$ & $2.03 \pm 0.43$ & 0.58 & $0.22-0.83$ & 2 \\
SD COP AP & $(\mathrm{cm})$ & $0.61 \pm 0.13$ & 0.37 & $0.02-0.71$ & 5 \\
range COP AP & $(\mathrm{cm})$ & $2.75 \pm 0.41$ & 0.25 & $-0.08-0.63$ & 9 \\
RMS area & $(\mathrm{mm})$ & $204.6 \pm 69.7$ & 0.48 & $0.14-0.78$ & 3 \\
\hline
\end{tabular}

$\mathrm{TTB}=$ time to boundary, abs $\mathrm{min}=$ absolute minimum, $\mathrm{SD}=$ standard deviation, $\mathrm{mv}=$ mean velocity, $\mathrm{COP}=$ center of pressure, $\mathrm{RMS}=$ root mean square, $\mathrm{ICC}=$ intraclass correlation coefficient, $95 \% \mathrm{CI}$ of ICC $_{2.1}: 95 \%$ confidence interval of ICC, $\mathrm{k}=$ the number of measurement times required to give an ICC value greater than 0.75 .

The values of TTB SD and TTB mean valley estimated in our study are lower than previously reported values ${ }^{7,8)}$. The minimum TTB peaks occur at some combination of velocity and distance from the stability boundary, but not necessarily at the maximum velocity and not at the minimum distance. Considering the mv COP estimates in our study were similar to those of previous studies ${ }^{7,8)}$, TTB SD and TTB mean valley might be influenced by the distance between location of COP and the border of the foot. It is theorized that a lower TTB minimum indicates propensity to postural instability because of the reduced time available to execute a postural correction $^{6}$. However, we think that a decreased distance to the stability boundary is not always associated with postural instability, if the subject can execute a postural correction near the boundary of the base of support. Individual differences in body sway are influenced by physique such as joints and bearing ${ }^{13)}$. Previous studies have reported that there are significant gender differences in several body sway parameters, and the relationship between COP sway and muscle strength during single-leg standing ${ }^{13,14)}$. Thus, the reason for the decreased distance between the location of COP and the border of the foot might be partly due to our data having been largely collected from young healthy males, unlike previous studies.

This study had a few limitations. Our results were derived from only 10 seconds data of COP excursion sampled at $50 \mathrm{~Hz}$ from young healthy adults. Therefore, generalization of our findings to other populations cannot be made without further investigation. In addition, this study did not generate enough data to confirm gender differences in postural control during single-leg standing. In a further study, it will be necessary to address the gender differences of postural control during single-leg standing.

\section{REFERENCES}

1) Murray MP, Seireg A, Scholz RC: Center of gravity, center of pressure, and supportive forces during human activities. J Appl Physiol, 1967, 23: 831-838. [Medline]

2) Goldie PA, Bach TM, Evans OM: Force platform measures for evaluating postural control: reliability and validity. Arch Phys Med Rehabil, 1989, 70: 510-517. [Medline]

3) Geurts AC, Nienhuis B, Mulder TW: Intrasubject variability of selected force-platform parameters in the quantification of postural control. Arch Phys Med Rehabil, 1993, 74: 1144-1150. [Medline]

4) Hertel J, Buckley WE, Denegar CR: Serial testing of postural control after acute lateral ankle sprain. J Athl Train, 2001, 36: 363-368. [Medline]

5) Duarte M, Zatsiorsky VM: On the fractal properties of natural human standing. Neurosci Lett, 2000, 283: 173-176. [Medline] [CrossRef]

6) van Wegen EE, van Emmerik RE, Riccio GE: Postural orientation: age-related changes in variability and time-to-boundary. Hum Mov Sci, 2002, 21: 61-84. [Medline] [CrossRef]

7) Hertel J, Olmsted-Kramer LC, Challis JH: Time-to-boundary measures of postural control during single-leg quiet standing. J Appl Biomech, 2006, 22: 67-73. [Medline]

8) Hertel J, Olmsted-Kramer LC: Deficits in time-to-boundary measures of postural control with chronic ankle instability. Gait Posture, 2007, 25: 33-39. [Medline] [CrossRef]

9) Pope M, Chinn L, Mullineaux D, et al.: Spatial postural control alterations with chronic ankle instability. Gait Posture, 2011, 34: 154-158. [Medline] [CrossRef]

10) Shrout PE, Fleiss JL: Intraclass correlations: uses in assessing rater reliability. Psychol Bull, 1979, 86: 420-428. [Medline] [CrossRef]

11) Bravo G, Potvin L: Estimating the reliability of continuous measures with Cronbach's alpha or the intraclass correlation coefficient: toward the integration of two traditions. J Clin Epidemiol, 1991, 44: 381-390. [Medline] [CrossRef]

12) Doyle TL, Newton RU, Burnett AF: Reliability of traditional and fractal dimension measures of quiet stance center of pressure in young, healthy people. Arch Phys Med Rehabil, 2005, 86: 2034-2040. [Medline] [CrossRef]

13) Kitabayashi $T$, Demura S, Noda M, et al.: Gender differences in body-sway factors of center of foot pressure in a static upright posture and under the influence of alcohol intake. J Physiol Anthropol Appl Human Sci, 2004, 23: 111-118. [Medline] [CrossRef]

14) Jonsson E, Seiger A, Hirschfeld H: One-leg stance in healthy young and elderly adults: a measure of postural steadiness? Clin Biomech (Bristol, Avon), 2004, 19: 688-694. [Medline] [CrossRef] 